\title{
AS RELAÇÕES ENTRE TRABALHO E EDUCAÇÃO: análise da constituição das escolas técnicas
}

Vera Lucia Martiniak

Universidade Estadual de Ponta Grossa

Programa de Pós-Graduação em Educação

\section{RESUMO:}

Este texto apresenta uma análise sobre a constituição das escolas técnicas no Paraná no início do século XX, tendo como eixo central da discussão a relação entre o trabalho e a educação. Primeiramente, a análise centra-se sobre a institucionalização dos abrigos para os menores, como forma de retirar os delinqüentes e desvalidos que perambulavam pelos centros urbanos. Num segundo momento, a análise incide sobre a formação do trabalhador para a agricultura e os interesses do governo em racionalizar e aumentar a lucratividade deste setor. Este texto discute as iniciativas para a organização do ensino agrícola no Brasil e em especial no Paraná, e procura compreender o papel desempenhado pelo ensino destas instituições escolares. Essas escolas eram destinadas aos filhos de agricultores, entretanto, sua gênese reside na criação dos patronatos e dos abrigos para menores, cujo objetivo era atender à infância desvalida do Estado. O ensino agrícola tinha, portanto, um duplo sentido: o primeiro seria a formação da mão de obra para os filhos de agricultores e a consequente melhoria da produção agrícola, em virtude do uso de técnicas e máquinas modernas; e o segundo, sob a égide do assistencialismo, seria a utilização do trabalho agrícola como um instrumento disciplinador do futuro trabalhador.

Palavras-chave: ensino técnico, trabalho, educação

\section{THE RELATION BETWEEN WORK AND EDUCATION: notes on the historical constitution of technical schools}

\begin{abstract}
This text presents an analysis of the constitution of technical schools in Paraná in the early twentieth century, with the central axis of the discussion the relationship between work and education. Firstly, the analysis concentrates on the institutionalization of shelters for minors, as a way to remove the criminals and the destitute roaming the urban centers. Secondly, the analysis focuses on the training of workers for agriculture and the interests of the government to streamline and increase the profitability of this sector. This paper discusses the initiatives for the organization of agricultural education in Brazil and especially in Paraná, and seeks to understand the role of the teaching of these schools. These schools were intended for the sons of farmers, however, its origin lies in the creation of patronatos and shelters for minors, which aimed to attend the child's helpless state. The agricultural teaching therefore had a double meaning: the first would be the formation of labor for the children of farmers and the improvement of agricultural production, due to the use of modern techniques and machinery, and the second under the aegis of welfare , would be the use of agricultural labor as a disciplinary tool of the future worker.
\end{abstract}

Keywords: technical education, work, education 


\section{INTRODUÇÃO}

Este artigo trata da constituição das escolas técnicas no Paraná no início do século XX e a organização das instituições escolares para atender aos interesses do governo no início da industrialização no país. Num primeiro momento, a análise centra-se sobre a institucionalização dos abrigos para os menores, como forma de retirar os delinqüentes e desvalidos que perambulavam pelos centros urbanos. Num segundo momento, a análise incide sobre a formação do trabalhador para a agricultura e os interesses do governo em racionalizar e aumentar a lucratividade deste setor.

Assim, este texto discute as iniciativas para a organização do ensino agrícola no Brasil e em especial no Paraná, e procura compreender o papel desempenhado pelo ensino destas instituições escolares. Essas escolas eram destinadas aos filhos de agricultores, entretanto, sua gênese reside na criação dos patronatos e dos abrigos para menores, cujo objetivo era atender à infância desvalida do Estado. O ensino agrícola tinha, portanto, um duplo sentido: o primeiro seria a formação da mão de obra para os filhos de agricultores e a consequente melhoria da produção agrícola, em virtude do uso de técnicas e máquinas modernas; e o segundo, sob a égide do assistencialismo, seria a utilização do trabalho agrícola como um instrumento disciplinador do futuro trabalhador.

Para desenvolvimento do texto, procura-se discutir os interesses e estratégias mobilizadas pelo Estado em torno da formação do trabalhador, concretizados por meio da criação das escolas técnicas. Assim, num primeiro momento apresenta-se as configurações que o trabalho assumiu ao longo da história da humanidade e no segundo momento, articula-se a discussão com a educação e a formação de mão de obra para a sociedade capitalista. Parte-se do entendimento de que a educação é determinada pelo modo de produção da vida material, "[...] bem como pelas relações nela implicadas, quais sejam, as relações de produção e as forças produtivas são fundamentais para apreender a maneira que os homens vivem, pensam e transmitem ideias [...]" (LOMBARDI, 2011, p. 11).

\section{As mudanças no mundo do trabalho: do ócio à sociedade capitalista.}

O trabalho manual desde a Antiguidade clássica foi considerado com um aviltamento para o homem livre, pois desempenhar uma atividade manual era desonroso e cabia essa tarefa apenas aos escravos capturados nas guerras. Esta ideia mudou a partir do colapso do Império romano e o advento da sociedade feudal, onde o artesanato ficou restrito às cortes senhoriais e encontrou nos mosteiros o espaço para sua difusão, porém numa concepção de mundo diferente da anterior - o catolicismo. Assim, o ócio passou a ser considerado como um vício e o trabalho manual como condição para a virtude. A sociedade passou a ser regida pelos valores cristãos que encontrou na Igreja ideais baseados na fraternidade e civilidade como motor do processo de renovação da vida social (CAMBI, 1999).

A ideia embrionária do catolicismo procurou estabelecer um modelo de sociedade colaborativa e orgânica se contrapondo aos valores do mundo antigo. Assim, até o próprio conceito de trabalho alterou-se gradativamente devido aos ideais de igualdade e solidariedade, onde o fator religioso tornou-se o centro da cultura. A escravidão passou a ser recriminada e o trabalho enaltecido para combater o ócio e também para que o homem produzisse seu próprio alimento. As relações do modo de produção baseavam-se na servidão dos camponeses aos senhores feudais que por meio do excedente que retiravam de suas terras se apropriavam pela instituição dos tributos feudais. A situação de submissão 
dos camponeses justificava-se em razão da proteção que o senhor feudal prometia, onde os trabalhadores tinham a posse dos meios de produção, mas não a sua propriedade.

A retomada do crescimento econômico alterou-se a partir do momento em que o produtor direto passou a trocar o excedente produzido no feudo por produtos que não poderia produzir. Com isso, surgiram os intermediários entre os feudos, os mercadores, que passaram a organizar a venda dos produtos por meio de feiras e mercados. "O simples crescimento deste comércio inevitavelmente criou condições rudimentares para um precoce capitalismo industrial" (HOBSBAWM, 2009, p. 46). À medida que o modo de produção feudal foi se alterando, alterou-se também, neste contexto o trabalho e a sua especialização. Mudaram as técnicas e com isso o trabalho também se transformou, reunindo indivíduos com conhecimentos especializados e interesses comuns nas corporações, que se tornou o lugar da formação profissional (CAMBI, 1999).

A constituição da sociedade burguesa no mundo ocidental resultou no depreciamento do trabalho manual e o enfraquecimento das corporações de ofícios mecânicos em diversos países da Europa. $O$ trabalho passou por uma nova reconfiguração nos quais os laços, entre o senhor e o servo, são dissolvidos e as relações de troca intensificaram-se entre comerciantes e produtores.

Assim, a expropriação e a expulsão da população rural proporcionaram à indústria urbana massas de proletários que venderam sua força de trabalho e tornaram-se assalariados. Os produtos que antes eram repartidos entre os pequenos produtores, agora, concentraram-se nas mãos de um capitalista. Antes, a família camponesa produzia e elaborava os meios de subsistência, as matérias-primas, que eram, na sua maior parte, consumidos por ela mesma, agora esses meios transformaram-se em mercadorias.

A burguesia se constituiu e se afirmou como classe dominante a partir de um conjunto de acontecimentos em determinada época histórica. Isto se decorreu do desenvolvimento do comércio e das navegações, as conquistas das colônias e dos novos mercados, o desenvolvimento da indústria (da manufatura, da pequena indústria até a grande indústria), a criação dos mercados mundiais. A burguesia é, portanto, produto histórico deste processo de mudanças, de um processo histórico e econômico em desenvolvimento.

No fim do século XIX, no Brasil, com a transição de uma organização social de trabalho escravo para uma organização de trabalho assalariado, começou a surgir, em vários locais, núcleos de pequenas propriedades agrícolas de base familiar. Para suprir a demanda de mão de obra nas grandes fazendas surgiram os núcleos de colonização estrangeira, principalmente no Sul do país. As relações de produção centradas no senhor e no escravo foram substituídas pela relação entre o capitalista e o empregado, os quais passaram a constituir a nova estrutura econômica da sociedade.

As relações de produção são constituídas pela propriedade econômica das forças produtivas. No capitalismo, a mais fundamental dessas relações é a propriedade que a burguesia tem dos meios de produção, ao passo que o proletariado possui apenas a sua forma de trabalho (BOTTOMORE, 1988, p. 157).

As relações de produção se consolidaram, ao longo do século XX, com a expansão da indústria e a consequente modernização do setor agrícola. A indústria brasileira ocupou uma posição subordinada à economia agroexportadora, posição que se alterou com a crise de 1929-30, com a evolução de uma economia industrializada, voltada para a substituição de importações. Na sociedade capitalista, a agricultura transformou-se em ramos da indústria e tornou-se dominada completamente pelo capital (MARX, 1982). 
Nesse cenário, a educação passou, então, a ser considerada como fator fundamental para o desenvolvimento do país, e deveria ser estendida à população, com o intuito de promover o aperfeiçoamento do indivíduo e da sociedade. Entretanto, a instabilidade política vivenciada pelo país nesse período e o domínio das oligarquias regionais, acentuaram as desigualdades sociais e impediram uma mudança qualitativa na educação. A União ampliou o ensino médio e superior nas regiões urbanas do país, porém, a formação técnico-científica ficou abandonada, apesar do relativo crescimento industrial.

Esse crescimento industrial, tão lento e incipiente que não acarretava por si mesmo a exigência de qualificação para o trabalho, mas que representava um salto qualitativo no avanço das relações de produção no país, acabou por fortalecer a difusão da ilusão liberal de ascensão social pela escolarização, que a própria aceleração do progresso imigratório estimulava (XAVIER, 1990, p. 62).

Com a crise mundial de 1929 ocorreu o declínio das oligarquias rurais e no ano seguinte, a chegada de Getúlio Vargas ao poder. Esse momento foi caracterizado pela intervenção estatal na vida econômica e social do país, nacionalizando as atividades e as fontes de riqueza nacional. A Constituição de 1937 ampliou o ensino técnico e vocacional, e estabeleceu a cooperação entre a indústria e o Estado, incumbindo às empresas de criarem escolas de aprendizes para os filhos de seus operários e associados.

Nesse mesmo ano, a Reforma Francisco Campos, de 1931, reestruturou o ensino no país, reformulando o ensino superior, secundário e profissional. A Reforma foi "[...] marco da arrancada centralizadora do governo provisório e síntese privilegiada das tendências predominantes no campo educacional" (IBID, 1990, p. 84), e efetivou-se por meio de decretos que dispunham sobre a organização do ensino superior, secundário e profissional.

No aspecto legal, a preocupação voltou-se para o ensino secundário e superior, pois o primeiro era considerado uma etapa de preparação para a matrícula nos cursos superiores. $\mathrm{O}$ ensino secundário caracterizou-se por sua função meramente preparatória e propedêutica, que valorizava provas e exames. Com essa reforma, a formação técnica e a escola estavam subordinadas ao avanço das relações de produção vigentes na sociedade e assim, admitiu-se o "[...] extremo atraso do país no campo econômico e consequentemente na área tecnológica ou dos meios de produção" (IBID,1990, p. 101).

Para acompanhar as exigências desse novo período, as classes trabalhadoras urbanas, à medida que avançavam as relações de produção e a sociedade se complexificava, "[...] passavam a ver na instituição escolar um mecanismo de acesso às novas relações de produção" (MIGUEL, 1997, p. 17).

A partir do processo de industrialização do país, verificou-se um crescimento da demanda social por escola, juntamente com a mobilização das elites intelectuais em torno da reforma e da expansão educacional. A necessidade de educação não era percebida como fundamental e foi, portanto, relegada a segundo plano pelo poder político, induzindo profundas modificações no quadro das aspirações educacionais, no discurso e na ação do próprio Estado (XAVIER, 1990).

Com a crescente industrialização no país ocorreu a expulsão do homem do meio rural para as cidades, que se modernizavam e expandiam-se. Para amenizar este problema, uma das estratégias encontrada foi a criação de escolas destinadas ao ensino agrícola, que tinham como objetivo formar mão de obra preparada para exercer as atividades agrícolas e auxiliar a fixação do homem no campo. Por outro lado, esta estratégia também amenizava 
o número crescente de delinqüentes e mendigos que perambulavam pelos centros urbanos, que tinham destinado certo nas escolas agrícolas.

A preocupação do Governo Estadual em oferecer o ensino agrícola aos menores desvalidos pode ser compreendida por meio da noção de que a solução para os problemas do Estado viria do progresso da agricultura nacional. Está idéia estava expressa nos Relatórios dos governantes estaduais, pois o Estado do Paraná era considerado "celeiro do Brasil", onde "[...] a fertilidade de suas terras attrahe diariamente a acção dos capitalistas e a corrente de immigração [...], por isso a preocupação constante com "[...] essa nova e extraordinaria fonte de receita publica [...] (PARANÁ, 1924, p. 48).

No Estado do Paraná, assim como em todo o país, a preocupação era com o atendimento aos menores, principalmente devido ao crescimento da população nos centros urbanos, onde se buscavam melhores condições de vida e de trabalho. Com o crescimento dos centros urbanos, houve um aumento considerável de mão de obra ociosa: desocupados, mendigos, menores abandonados e delinqüentes que perambulavam pelas ruas da cidade.

Ao solucionar a formação de mão de obra, por meio da educação profissional, o Governo também resolveria, parcialmente, a questão do aumento da pobreza nas cidades com a criação das instituições de assistência e de disciplinamento dos menores.

Seguindo um movimento internacional de atendimento à infância, o Interventor Manoel Ribas, nos primeiros anos de sua administração, procurou criar escolas que atendessem aos filhos de agricultores e às crianças desvalidas. Por isso, implantou no Estado a educação profissional para a formação técnica,

[...] onde os meninos desprotegidos, órfãos ou abandonados, bem como os filhos de lavradores pobres, tivessem instrução indispensável para tornar-se trabalhadores eficientes, com a posse de conhecimentos que tornam capaz o agricultor (PARANÁ, 1932, p. 60-1).

A preocupação com as questões sociais foi solucionada pelo setor educacional que procurou disciplinar a força de trabalho, servindo como instrumento de solidificação da sociedade capitalista. O ideário republicano centrou-se na civilização e formação de um cidadão voltado para o projeto nacional, atribuindo ao ensino à formação necessária para o desenvolvimento da nação. Do ponto de vista ideológico, o discurso produzido enfatizava que pela educação e pelo trabalho o trabalhador poderia alcançar sua autonomia, entretanto para os grupos hegemônicos, o disciplinamento atendia os interesses e redefinições do capital.

Nas iniciativas empregadas pelo Governo, tanto Federal quanto Estadual, mantevese presente um dualismo educacional, que se refletiu em uma educação para o povo - a educação para o trabalho $\square$, e uma educação para a elite, voltada para a formação cultural. "A escola primária e as escolas profissionais eram instituições do primeiro grupo e a escola secundária e as escolas superiores, instituições de segundo grupo" (CUNHA, 2005a, p. 172).

Com a preocupação voltada para a urbanização do Estado e para seu crescimento econômico, foram criadas as escolas técnicas agrícolas.

A iniciativa do Governo Estadual em criar as escolas técnicas agrícolas não aconteceu por mero acaso ou por altruísmo da administração, mas pela confluência de vários fatores econômicos, políticos e sociais que culminaram com o processo de formação da mão de obra para o trabalho, sob a ideologia do atendimento e da assistência aos desvalidos.

Durante o período de interventoria no Estado, os Relatórios, apesar de escassos e sucintos, apontavam a preocupação com a agricultura como fator para o desenvolvimento 
econômico e para a pluralidade de culturas agrícolas que estavam se formando, depois do declínio da erva-mate (PARANÁ, 1935). Diante do crescimento da cultura do café e do algodão no Estado, surgiu o desafio e a necessidade de fortalecer o ensino oferecido aos agricultores, mediante a Seção de Educação Profissional, do Departamento de Agricultura do Estado.

Concomitante à preocupação com o desenvolvimento da agricultura, o Governo procurou soluções para o problema da infância desprotegida, aliando-o, de forma racional, à formação técnica nas instituições que formavam os trabalhadores rurais. A matrícula na instituição era prioritária aos órfãos e aos menores desamparados, com idade mínima de 9 anos e máxima de 18, como medida para solucionar o problema do abandono familiar, podendo ser matriculados, ainda, os filhos de lavradores. Desta forma, tentava-se solucionar o problema do abandono familiar e o da formação de trabalhadores para a agricultura.

\section{O ensino oferecido pelas instituições técnicas agrícolas no Paraná.}

O ensino proporcionado aos menores desvalidos e aos filhos de agricultores explicitou a organização didático-pedagógica e a educação que se desejava oferecer, ou seja, um ensino eminentemente prático, voltado para a formação de trabalhadores necessários para a manutenção de uma elite oligárquica no poder.

As escolas rurais ministravam o curso primário regido por professores normalistas, que obedeciam às instruções da Diretoria de Educação Pública. "Ao mesmo tempo recebem, os alunos, ensinamentos práticos de agricultura, horticultura, jardinaria, silvicultura, higiene e trato dos animais, laticínios, avicultura e outros" (PARANÁ, 1932, p. 39). As aulas teóricas possuíam uma carga horária semanal de três aulas e as práticas de, no mínimo, duas horas, distribuídas de acordo com a necessidade do ensino; sugeria-se, ainda, que o ensino se desse no campo, para facilitar o aprendizado do aluno.

Após os alunos concluírem o curso primário, nas escolas de trabalhadores rurais, eram transferidos para a escola da capital, onde prosseguiam seus estudos, os quais visavam à formação de Auxiliar Prático do Agrônomo, com conhecimentos gerais de agricultura e pecuária.

As escolas rurais foram criadas com o objetivo de formar profissionais para a agricultura, pois o Governo paranaense acreditava que o homem do campo não possuía as técnicas necessárias para tirar o melhor proveito do solo. Além das orientações de cunho agrícola, os alunos recebiam conteúdos do ensino primário regular, que se dividia em três cursos:

1) Primário, que seguia as orientações e os programas utilizados nas escolas primárias do Estado.

2) Complementar, que era ministrado em dois anos e dividido em quatro semestres.

3) Profissional, que era ministrado em dois anos e dividido em quatro semestres, com o objetivo de formar profissionais na área.

As escolas também deveriam receber matriculas de meninas, porém, no conteúdo curricular acrescentava-se a disciplina de trabalho doméstico. No entanto, apesar da garantia da matrícula nas instituições agrícolas, a predominância de meninos era bem maior.

Para os dirigentes do Estado, o ensino agrícola atingia os objetivos propostos para a formação do homem do campo, tendo atendido, até 1938, cerca de 380 alunos nas escolas rurais. Neste sentido, como forma de organização do ensino agrícola no Estado, o Governo 
estadual aprovou, por meio do Decreto $\mathrm{n}^{\mathbf{0}} 7.782 / 39$, de 06 de janeiro de 1939, o Regulamento das Escolas de Trabalhadores Rurais, sendo criados os cursos de Primário Agrícola e Agrícola Profissional. O curso Primário tinha duração de quatro anos, sendo, na primeira fase, semelhante ao ensino elementar dos grupos escolares do Estado. Conforme o Código de Ensino de 1917, ainda em vigor na década de 1930, dispunha, em seu programa, os conteúdos e os procedimentos de ensino a serem desenvolvidos em cada uma das séries. $\mathrm{O}$ programa para o ensino primário para os alunos das escolas de trabalhadores rurais era $\mathrm{o}$ mesmo do Estado, mas, simultaneamente, recebiam formação prática voltada para a agricultura e a pecuária. Poderiam ser matriculados alunos com idade entre 10 e 14 anos, bem como seriam atendidos, em regime de internato, os menores abandonados e os órfãos, conforme encaminhamento do Juizado de Menores do Estado.

O Programa para as Escolas Primárias Rurais compreendia as seguintes disciplinas: $1^{\circ}$ ano - Trabalhos com instrumentos e máquinas agrícolas elementares de acordo com o físico do aluno. Serviço de lavras, destorramento e semeadeiras.

$2^{\text {o }}$ ano - Serviço de irrigação de plantações e de aplicação de adubos orgânicos e químicos. Multiplicação de plantas ornamentais. Escrituração agrícola elementar.

$3^{\circ}$ ano - Plantio e corte de gramados. Enxertos e podas de plantas ornamentais e de árvores frutíferas. Colheita de flores, legumes e frutos. Embalagem, conservação e acondicionamento. Multiplicação de plantas ornamentais por meio de sementes, estacas, mergulho e enxertia.

$4^{\mathrm{o}}$ ano - Trabalhos práticos especializados em: laticínios, apicultura, sericultura, noções de redação e contabilidade agrícola; trabalhos em ferro, couro e madeira nas oficinas; drenagem e irrigação; avicultura; emprego de inseticidas e fungicidas; zootecnia, veterinária, as sementeiras e os viveiros, podas; campos de criação, conhecimento sobre raça de animais, doenças mais comuns e tratamento, serviços de culturas em fazendas de criação. (PARANÁ, 1939, art. $8^{\circ}$ ).

Já o curso Agrícola Profissional era ministrado em três anos, distribuído em oito cadeiras, e, ao término do curso, o aluno recebia o título de Capataz Rural. Para ingresso na Instituição, o candidato deveria ter entre 14 e 18 anos de idade, ter frequentado o curso primário e o último ano do Curso Primário Agrícola e ter sido encaminhado por uma autoridade competente, neste caso, o Juizado de Menores.

O Regulamento explicitava os objetivos a que se destinavam as escolas de trabalhadores rurais, ou seja, eram internatos de ensino público destinado ao preparo de profissionais para a agricultura, de acordo com as necessidades técnico-práticas da lavoura e da pecuária.

Criadas e mantidas pelo Governo Estadual, essas escolas deveriam, de modo progressivo, manter-se economicamente por meio da produção da sua lavoura. As escolas ofereciam, também, o ensino agrícola para as mulheres, porém funcionavam em prédios distintos e independentes. O ensino destinado ao público feminino era acrescido de educação doméstica “[...] a fim de torná-la ótima dona de casa rural” (PARANÁ, 1939, $\operatorname{artigo} 6^{\circ}$ ).

$\mathrm{Na}$ organização das escolas eram oferecidos os seguintes serviços aos internos: assistência alimentar, higiênica, sanitária e educacional, oficinas para trabalhos com ferro, madeira e couro, campo de culturas, posto zootécnico e campo de criação.

Ressalta-se, ainda, que, no Regulamento das Escolas, de 1939, constata-se o ensino eminentemente prático, em que o aluno, por meio de várias disciplinas de teor prático, deveria aprender fazendo.

Com a organização do ensino agrícola e com a aprovação do Regulamento para as Escolas de Trabalhadores Rurais, o Relatório do Interventor Manoel Ribas, enviado ao 
Presidente Getulio Vargas, em 1942, apresentava um tom otimista em relação ao ensino público no Estado. No Relatório, o Interventor enaltecia a preocupação com a campanha de alfabetização e a incrementação da educação integral.

A demanda por escolas, no Paraná, intensificou-se, principalmente, nas décadas de 1940 e 1950, à medida que se consolidou o processo de ocupação e colonização do território paranaense; outro fator que acelerou essa demanda foram as reivindicações na participação dos bens sociais pelas classes trabalhadoras nos núcleos urbanos emergentes, que se fizeram de modo mais veemente (MIGUEL, 1992). Entretanto, o Governo paranaense atendeu às necessidades educacionais da maioria da população urbana quanto ao ensino primário, mas nas áreas rurais, devido à colonização tardia, criou-se uma demanda maior pelo ensino primário público, fazendo com que, nas décadas seguintes, as reivindicações se voltassem para os níveis profissionalizantes do ensino. Até o início da década de 1940, o Paraná contava com dez escolas de trabalhadores rurais e duas escolas de pescadores no Estado. Entretanto, a criação das escolas de trabalhadores rurais evidenciou como a característica do atendimento aos menores nessas instituições, que, predominantemente, se tornaram de "assistência aos pobres e aos delinquentes". Também fica evidente, na leitura dos Relatórios da época, que utilizavam os termos "infância desamparada", "menores com desvios de condutas" e "menores abandonados" para definir o público a que se destinava o atendimento nas escolas de trabalhadores rurais.

O objetivo inicial seria a formação de trabalhadores rurais, porém a assistência aos menores sobressaiu-se como solução para a pobreza em que se encontravam as famílias do interior e para amenizar o crescimento da delinquência no Estado.

$\mathrm{O}$ atendimento das instituições agrícolas era precário e as dificuldades encontradas pelas escolas de trabalhadores rurais foram atribuídas ao fato de estarem subordinadas à Secretaria de Agricultura, à qual estiveram atreladas desde seu início. Desde a instalação da República, o ensino agrícola no país, foi vinculado ao Ministério da Agricultura, Indústria e Comércio e, apesar da criação do Ministério da Educação e Saúde, em 1930, o ensino agrícola permaneceu sob a tutela do Ministério da Agricultura. Em 1940, reafirmouse tal dependência, com a criação da Superintendência do Ensino Agrícola e Veterinário (SEAV), órgão ligado ao Ministério da Agricultura que controlava os estabelecimentos que ofereciam o ensino agrícola.

Com a base da economia brasileira agroexportadora, o governo getulista equilibrou os interesses da classe dominante com os diferentes setores agrícola e industrial. Apesar do período conflituoso da Segunda Guerra Mundial e do desenvolvimento do capitalismo, a educação manteve-se à margem da necessidade de formação para o trabalho, pois as atenções estavam voltadas para a defesa nacional.

O Presidente da República, Getúlio Vargas, implantou o Plano Especial de Obras e Aparelhamento da Defesa Nacional. No período conflituoso da Guerra, intensificaram-se o interesse e os acordos de cooperação técnica de algumas instituições privadas estadunidenses com o Ministério da Agricultura. Em 1945 firmou-se, entre o Ministério da Agricultura e uma agência privada norte-americana, o segundo grande acordo de cooperação técnica no âmbito da Educação Rural, materializado na Comissão BrasileiroAmericana de Educação das Populações Rurais - CBAR, (MENDONÇA, 2010). Esses acordos visavam à implantação de Centros de Treinamento (CTs) destinados, exclusivamente, à qualificação profissional de trabalhadores rurais adultos; a difusão nacional de Clubes Agrícolas Escolares para infância e juventude; a formação continuada de técnicos especializados nos EUA e a preparação de "lideranças rurais", por meio de programas educativos teoricamente capazes de incutirem, nos trabalhadores do campo, o "amor à terra e ao trabalho". 
Essas experiências decorreram da conjuntura internacional inaugurada pelo fim da II Guerra e início da Guerra Fria, quando emergiram construtos como desenvolvimento e Terceiro Mundo, viabilizados a partir de discursos e práticas pautados pela ideia de crescimento econômico e seus supostos benefícios (MENDONÇA, 2010, 191).

O avanço do setor industrial e os investimentos financeiros no campo provocaram a modernização da agricultura e a consequente demanda de formação técnica, provocando uma maior expectativa sobre a formação de mão de obra para este setor.

Durante seu governo, Getúlio Vargas articulou, engenhosamente, os interesses das elites e dos setores vinculados ao capital industrial. Convém lembrar, ainda, que incorporou muitas das reivindicações trabalhistas, mas, ao mesmo tempo, estabeleceu dispositivos tutelares para cercear a atuação política dos trabalhadores (MANFREDI, 2002). No setor educacional, favoreceu os interesses dos setores empresariais privados e estatais, em detrimento dos interesses dos grupos populares. Para adequar o ensino promoveu reformas que se deram na forma de Decretos-Leis, denominadas de Leis Orgânicas, que trataram, individualmente, de cada nível ou ramo de formação profissional, ordenando o ensino primário, secundário, industrial, comercial, normal e agrícola. As reformas implementadas por Gustavo Capanema iniciaram-se em 1942 e foram finalizadas em 1946, com Lei Orgânica do Ensino Agrícola. Como se observa, tais Leis não seguiram uma ordem lógica, mas foram, na verdade, resultados de arranjos políticos (SAVIANI, 2007).

Os demais ramos do ensino médio tinham a finalidade de formar uma força de trabalho especificada para os setores da produção e da burocracia: o ensino agrícola, para o setor primário; o ensino industrial para o setor secundário; o ensino comercial para o setor terciário; e o ensino normal, para a formação de professores para o ensino primário (CUNHA, 2005b, p. 41).

Essas Leis, do ponto de vista da sua concepção, tinham um caráter dualista e corporativista; o primeiro porque separavam o ensino destinado às elites condutoras do ensino destinado ao povo; o segundo porque vinculava "[...] estreitamente cada ramo ou tipo de ensino às profissões e ofícios requeridos pela organização social" (SAVIANI, 2007, p. 269).

Com a aprovação da Lei Orgânica do Ensino Agrícola, em 1946, ficou estabelecida a base da organização e do regime do ensino agrícola, destinado, essencialmente, à preparação profissional dos trabalhadores da agricultura. $\mathrm{O}$ ensino agrícola objetivou formar profissionais aptos às diferentes modalidades de trabalhos agrícolas, oferecendo aos jovens e adultos uma qualificação profissional que aumentasse sua eficiência e produtividade, bem como aperfeiçoasse os conhecimentos e as capacidades técnicas de trabalhadores agrícolas diplomados e, também tinha por objetivo formar professores de disciplinas próprias desse ensino.

Mesmo com a promulgação da Lei Orgânica do Ensino Agrícola, as escolas continuaram sob a competência do Ministério da Agricultura, por isso a preocupação do Governo Estadual em manter um regime de colaboração com a União, que deveria auxiliar na manutenção dessas instituições.

Nesse contexto de reformas na legislação educacional, as Leis Orgânicas oficializaram o dualismo educacional brasileiro, que reproduziu - por meio da estrutura do 
sistema educacional - a discriminação e os privilégios da estrutura econômico-social, mantidos e garantidos tanto no regime político "democrático" como no "autoritário". Assim, a "[...] política educacional nacional definia-se, cada vez mais nitidamente, como instrumento de cimentação da ordem econômico-social vigente" (XAVIER, 1990, p. 119).

Essa política referente ao ensino brasileiro se manteve até a Constituição de 1946, a qual determinou as diretrizes educacionais que se refletiram na primeira Lei de Diretrizes e Bases da Educação Nacional, aprovada em 1961. Durante o período de tramitação da Constituição, de 1946 até a LDB 4024/61, o país assistiu a uma crescente urbanização, forjada a partir da década de 1930, o que ocasionou um aumento na classe proletária.

A Lei 4.024, de 20 de dezembro de 1961, foi a primeira a definir a finalidade da educação. Manteve a estrutura educacional organizada da seguinte forma: ensino préprimário, escolas maternais e jardins de infância; ensino primário com duração de 4 anos, podendo ser acrescidos mais 2 anos para programas de artes aplicadas; ensino médio, subdivido em dois ciclos (ginasial de 4 anos e colegial de 3 anos), ambos compreendendo o ensino secundário e o ensino técnico (industrial, agrícola, comercial e de formação de professores); e ensino superior.

As instituições agrícolas têm em sua trajetória a marca do assistencialismo e da formação por meio do trabalho, preparando o trabalhador rural com conhecimentos básicos sobre técnicas agrícolas que atendessem às novas relações do capital. Conforme o contexto da época, o atendimento aos menores foi se transformando e se adaptando para atender às exigências do capital. Com o discurso de civilizar a sociedade, a classe dominante impôs sua ideologia utilizando, como um dos recursos, a educação da população. Decorrente disto, criou-se a elitização do ensino, que se dividia em dois: um voltado para formar a classe dirigente do país e outro para formar mão de obra preparada para atuar nas indústrias e também no campo (MARTINIAK, 2011).

\section{Considerações Finais}

Procurou-se apresentar e discutir o processo histórico de constituição das instituições técnicas agrícolas, tendo como referência a relação entre trabalho e educação.

Com esse balizamento, inferem-se algumas considerações a respeito das transformações que ocorreram nas orientações do modelo de escola agrícola, cujas características foram voltadas, primeiramente, para o atendimento aos desvalidos e, com as mudanças nas relações de produção, para a formação de mão de obra para a agricultura.

A gênese do ensino agrícola, no país, tem suas raízes alicerçadas no assistencialismo, como forma de corrigir as mazelas da sociedade e de "afastar" o menor da criminalidade e da ociosidade. A partir da década de 1930, com o desenvolvimento da industrialização e da urbanização das grandes cidades, as preocupações do Governo se voltaram para a formação do homem do campo, para o aprendizado e o cultivo do solo e para a utilização das máquinas agrícolas.

No Paraná, o Interventor Manoel Ribas, durante o período em que esteve à frente do governo, promoveu diversas medidas para expandir o ensino primário, o ensino normal e superior, bem como o ensino profissional. A ampliação das instituições escolares foi peça essencial na Campanha de Nacionalização, principalmente na integração dos estrangeiros aos valores nacionais. Durante seu governo foram criadas as Escolas de Trabalhadores Rurais que se constituíram instrumentos para a preparação da mão de obra para o setor agrícola.

O desenvolvimento do ensino agrícola no país subordinou-se aos ordenamentos do Ministério da Agricultura, inclusive com a indicação de Engenheiros Agrônomos para a 
direção das instituições escolares. No seu interior, a rígida disciplina esteve presente na legitimação da ordem e na formação moral dos internos, porém, os entusiasmados discursos da elite dirigente não garantiram a formação necessária para atuar no setor agrícola. As escolas de trabalhadores rurais, no Paraná, tinham uma estrutura precária, com carência de instalações e de máquinas agrícolas para o aprendizado das técnicas rurais. A intenção do Governo paranaense, ao criar essas escolas, respaldava-se no discurso da agricultura como elemento salvador da economia regional, tornando o Paraná o "Celeiro do Brasil"; mais do que isso, porém, objetivou formar trabalhadores com conhecimentos básicos sobre agricultura, que soubessem manejar o solo e as máquinas agrícolas, e fossem ajustados aos moldes da sociedade capitalista.

\section{Referências}

BOTTOMORE, Tom. Dicionário do Pensamento Marxista. Rio de Janeiro: Jorge Zahar Editora, 1988.

CAMBI, Franco. História da Pedagogia. São Paulo: Editora UNESP, 1999.

CUNHA, Luiz Antonio. O ensino de ofícios nos primórdios da industrialização. 2. ed. São Paulo: Editora UNESP; Brasília/DF: FLACSO Brasil, 2005a.

O ensino profissional na irradiação do industrialismo. 2.ed. São Paulo: Editora UNESP; Brasília/DF: FLACSO Brasil, 2005b.

HOBSBAWN, Eric J. A Era das Revoluções. São Paulo: Editora Paz e Terra, 2009.

MANFREDI, Sílvia Maria. Educação profissional no Brasil. São Paulo: Cortez, 2002.

MARX, Karl. Para a Crítica da Economia Política. Tradução de Edgar Malagodi... (et al). São Paulo: Abril Cultural, 1982.

MARTINIAK, Vera Lucia. Educação e Trabalho no Ensino Agrícola: História das instituições escolares agrícolas. Curitiba: Editora CRV, 2011.

MENDONÇA. Sonia Regina de. Extensão rural e hegemonia norte-americana no Brasil. História. Unisinos Maio/Agosto 2010. p. 188-196

MIGUEL, Maria Elizabeth Blanck. A formação do professor e a organização social do trabalho. Curitiba: Ed. UFPR, 1997.

PARANÁ. Mensagem dirigida ao Congresso Legislativo pelo Dr. Caetano Munhoz da Rocha, Presidente do Estado, ao instalar-se a $1^{\mathrm{a}}$. Sessão da $17^{\mathrm{a}}$. Legislatura 1/02/1924. Curityba: [s.n.], 1924.

Relatório apresentado ao Interventor Manoel Ribas, pelo Secretário de Estado dos Negócios da Fazenda e Obras Públicas, 1935.

Mensagem do Governador Manoel Ribas à Assembléia Legislativa. Curitiba: Imprensa Gráfica Paranaense, 1937. 
Decreto $\mathrm{n}^{\mathrm{o}} 7.782$, de 6 de janeiro de 1939. Aprova o Regulamento das Escolas de Trabalhadores Rurais no Estado. Diário Oficial do Estado do Paraná. Curitiba, 6 jan. 1939.

Mensagem apresentada à Assembleia Legislativa do Estado pelo Sr. Moyses Lupion, governador do Paraná. Paraná: Curitiba, 1950.

SAVIANI, Dermeval. História das Ideias Pedagógicas. São Paulo: Autores Associados, 2007.

SUTIL, Marcelo Saldanha. Beirais e Platibandas: A arquitetura de Curitiba na primeira metade do século 20. Curitiba, 2003. Tese (Doutorado em História).

XAVIER, M. E. S. P. Capitalismo e escola no Brasil. Campinas: Papirus, 1990.

Recebido em: $\quad 27.04 .12$

Aprovado em: 30.05 .12 : 